\title{
Influence of the volume of osteonecrosis on the outcome of core decompression of the femoral head
}

Bernard Mazières, Frédéric Marin, Philippe Chiron, Laurence Moulinier, Jean-Marc Amigues, Michel Laroche, Alain Cantagrel

\begin{abstract}
Objectives-To assess the outcome of core decompression in the treatment of osteonecrosis of the femoral head related to the volume of necrotic bone measured according to a previously reported method.

Methods-Twenty hips corresponding to strictly Ficat stage II underwent magnetic resonance imaging and the volume of necrotic bone was expressed as a percentage of the volume of the entire head measured on each slice. All hips underwent core decompression and the outcome was evaluated at 24 months. The primary evaluation criterion was radiological appearance: the outcome was considered as good if the hip remained stage II and poor if the disease progressed.

Results-Twenty four months after core decompression, half the cases remained stable and in half the disease had progressed. Outcome seemed to be related to the volume of necrotic bone (average $22 \%$ in the good outcome group versus $45 \%$ in the poor outcome group $(p=0.0051))$ and was independent of risk factors, age, and histological type.

Conclusions-The volume of necrotic bone should be taken into account in the evaluation of any treatment, bearing in mind that in more than one third of cases this volume will probably decrease, especially at the beginning of the disease process.
\end{abstract}

(Ann Rheum Dis 1997;56:747-750)

The treatment of osteonecrosis of the femoral head $(\mathrm{ON})$ remains controversial, both in the early stages of the disease when the femoral head is still spherical and in later stages when the head is flattened. ${ }^{1}$ In the first instance, core decompression is the classic treatment. A recent general review of the medical literature ${ }^{2}$

Accepted for publication 22 September 1997 concluded that core decompression of the femoral head and neck gave an overall $64 \%$ clinical success rate and $63 \%$ showed no disease progression on radiographs, compared with $23 \%$ and $27 \%$ respectively for conservative treatment. Total hip arthroplasty was later necessary in $80 \%$ of cases treated conservatively compared with $23 \%$ of those treated by core decompression.

Magnetic resonance imaging (MRI) makes it possible to diagnose $\mathrm{ON}$ in early stages when plain radiographs are still normal or non-specific. ${ }^{3}$ Several authors have also used this technique to classify the response to treatment according to the extent of necrosis. ${ }^{4-6}$ Using MRI, the volume of necrotic bone can also be measured and expressed as a percentage of the total volume of the femoral head. Three teams have evaluated the results of core decompression according to the extent of necrosis. ${ }^{7-10}$ They observed that only the extent of necrosis determined the outcome of the femoral head whether core decompression had been performed or not.

We reviewed the results of this treatment on non-traumatic osteonecrosis at an early stage and quantified the volume of necrotic bone by one of the methods proposed.

\section{Methods}

This retrospective study included 18 patients (20 hips) with stage II osteonecrosis according to Ficat (table 1), who all underwent core decompression of the femoral head.

\section{PATIENTS}

Sixteen men and two women were include in the study whose mean age was 43 years (range 26-63 years). All but one had bilateral ON. The 15 contralateral necrotic hips, not included in this study, were in most cases Ficat stage III (13 cases), one was stage I and one stage II. Of the 20 stage II hips that underwent core decompression, nine were asymptomatic. All patients presented risk factors: 10 received corticosteroid treatment, 11 admitted alcohol abuse, and one had gout. Alcohol abuse and corticosteroid treatment were associated in four cases (table 2).

STUDY DESIGN

The diagnosis of osteonecrosis was in all cases suspected on the radiological image that defined stage II (slightly mottled appearance of trabecular bone), and was confirmed by MRI 

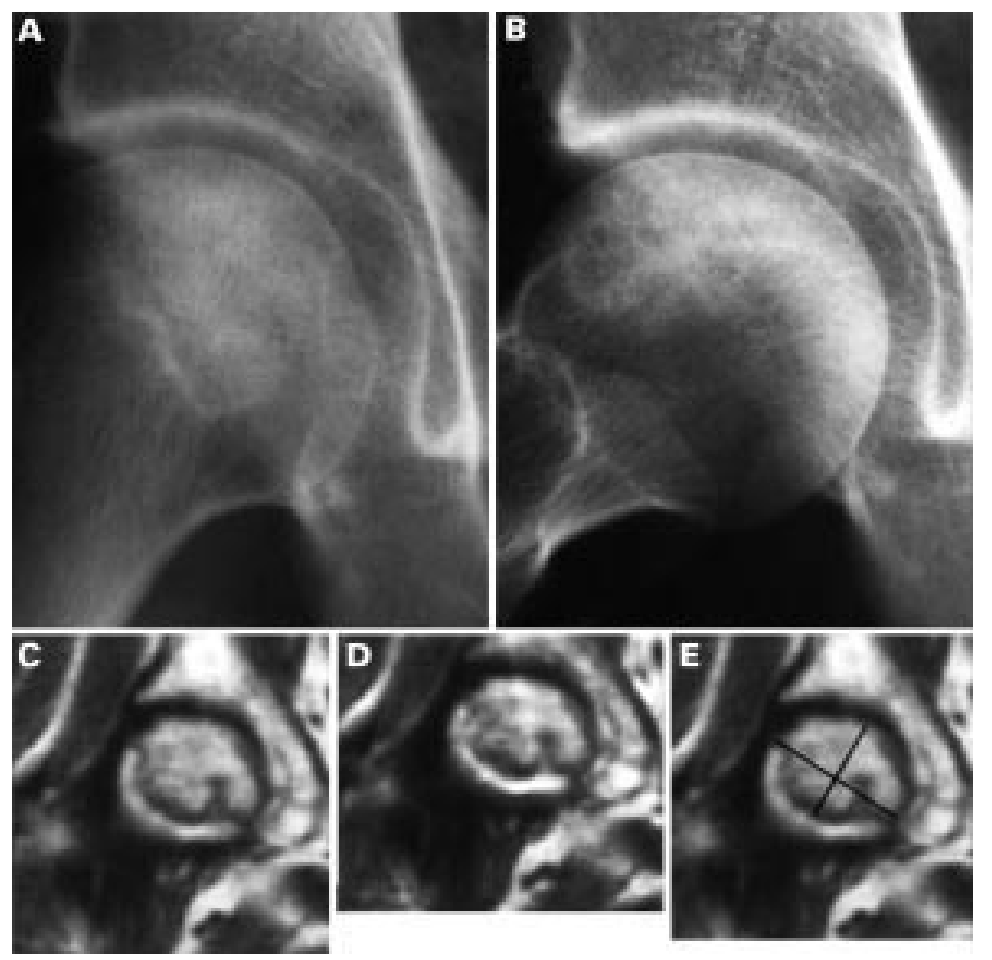

Figure 1 Case 2, 56 year old women. Right hip: (A) on AP view a linear sclerotic line at the junction of femoral head and neck delineates a sclerotic area in the centre of the head; (B) on profile, the sclerotic zone is limited to the anterosuperior part of the head. On both views the femoral head is spherical (stage II); (C) MRI, T1 weighted image (TE: $500 \mathrm{ms,}$ TR: $34 \mathrm{~ms}$ ) a concave superiorly low signal intensity line delineates the necrotic area; (D) T2 weighted image (TE: $2000 \mathrm{~ms}$, TR: $50 \mathrm{~ms}$ ) the same line is observed, with a high signal intensity band at the convex aspect of the line ("double rim sign"); (E) on the T1 weighted image, the necrotic area is assimilated to a rectangle whose length and width are measured with a magnifying glass graduated in tenths of a millimetre.

with $\mathrm{T} 1$ and $\mathrm{T} 2$ weighted sequences in contiguous $5 \mathrm{~mm}$ frontal slices, which showed the band of low signal intensity delineating the necrotic area on both sequences (fig 1). Before core decompression, anteroposterior and lateral radiographs and computed tomography of the hip were obtained in all patients to exclude early stage III disease (minimal subchondral fracture missed on standard radiographs). All patients underwent core decompression and in all cases the sample permitted histological study. Necrosis was found in all (table 2).

Postoperative follow up was 24 months and at the end of this period all patients underwent standard clinical and radiological examination.

The volume of necrotic bone was calculated on the T1 weighted frontal MRI slices according to the method of Holman et al. ${ }^{10}$ It was not possible to digitise the images to define the precise outline of the necrotic area indicated by the band of low signal intensity. Depending on the shape of the necrotic area, we therefore assimilated it either to a circle (fig 1), whose diameter we measured, or to a rectangle whose length and width were measured as proposed by Lafforgue et al. ${ }^{7}$ The area of the head was approximated to the circle in which it best fitted, whose diameter was measured. All these measurements were made on a light box using a magnifying glass graduated in tenths of a millimetre. For each slice, the area of necrotic bone thus obtained was calculated in relation to that of the head and the result expressed as a percentage. Slices on which no necrosis could be seen were counted $0 \%$. A mean of five slices per hip were studied. The sum of the areas calculated on each slice gave an indication of the true volume of the necrotic area. The same observer again calculated the volumes of necrosis of the 20 cases some weeks later. The intraobserver coefficient of variation was $8.4 \%$.

The main judgement criterion was the radiological appearance at two years. The outcome was considered good if the radiographic lesions were stable (unchanged stage II, with preservation of a round femoral head), and poor if the disease had advanced (progression to stage III : flattening, break in the articular margin or crescent sign). The secondary judgement criteria were clinical condition and need for total hip arthroplasty.

\section{STATISTICAL ANALYSIS}

The groups were compared using the MannWhitney non-parametric test for small samples

Table 2 Patient characteristics

\begin{tabular}{|c|c|c|c|c|c|c|c|c|c|c|c|c|}
\hline \multirow[b]{2}{*}{ Patient } & \multirow[b]{2}{*}{$\begin{array}{l}\text { Sex, } \\
\text { age }(y)\end{array}$} & \multicolumn{2}{|l|}{ Studied hip } & \multicolumn{2}{|c|}{ Opposite hip } & \multirow[b]{2}{*}{$\begin{array}{l}\text { Aetiological } \\
\text { factors }\end{array}$} & \multirow{2}{*}{$\begin{array}{l}\text { ON } \\
\text { volume } \\
(\%)\end{array}$} & \multirow[b]{2}{*}{$\begin{array}{l}\text { Histological } \\
\text { type }\end{array}$} & \multicolumn{3}{|c|}{ Status (at 2 years) } & \multirow[b]{2}{*}{ Outcome } \\
\hline & & Symptoms & $\begin{array}{l}\text { Radiological } \\
\text { stage }\end{array}$ & Symptoms & $\begin{array}{l}\text { Radiological } \\
\text { stage }\end{array}$ & & & & Symptoms & $\begin{array}{l}\text { Radiological } \\
\text { stage }\end{array}$ & Treatment & \\
\hline 1 & $M, 35$ & No & 2 & Yes & 3 & Alcohol & 32 & II & No & 2 & Conservative & Good \\
\hline 2 & F, 56 & No & 2 & Yes & 3 & Alcohol + CS & 54 & II & Worse & 3 & THR & $\mathrm{Bad}$ \\
\hline 3 & $M, 35$ & No & 2 & Yes & 3 & $\mathrm{CS}$ & 18 & IV & No & 2 & Conservative & Good \\
\hline 4 & $M, 48$ & Yes & 2 & Yes & 3 & $\mathrm{CS}$ & 33 & IV & Worse & 3 & THR & $\mathrm{Bad}$ \\
\hline 5 & $M, 63$ & Yes & 2 & No & Normal & Gout + CS & 38 & III & Worse & 3 & THR & $\mathrm{Bad}$ \\
\hline 6 & $M, 26$ & No & 2 & Yes & 3 & Alcohol & 26 & II & No & 2 & Conservative & Good \\
\hline 7 & $\mathrm{M}, 40$ & Yes & 2 & Yes & 3 & Alcohol & 21 & IV & Improved & 2 & Conservative & Good \\
\hline 8 & $M, 57$ & Yes & 2 & Yes & 3 & $\mathrm{CS}$ & 55 & III & Worse & 4 & THR & $\mathrm{Bad}$ \\
\hline 9 & $\mathrm{~F}, 50$ & Yes & 2 & No & 1 & SLE, CS & 10 & II & No & 2 & Conservative & Good \\
\hline 10 & $M, 60$ & Yes & 2 & Yes & 3 & SLE, CS & 18 & III & Worse & 2 & THR & $\mathrm{Bad}$ \\
\hline 11 & $M, 39$ & No & 2 & Yes & 3 & Alcohol & 5 & II & No & 2 & Conservative & Good \\
\hline 12 & $M, 36$ & Yes & 2 & No & 2 & Alcohol & 90 & III & Worse & 3 & THR & $\mathrm{Bad}$ \\
\hline $13 \mathrm{R}$ & $M, 42$ & No & 2 & - & - & CS & 19 & III & No & 2 & Conservative & Good \\
\hline $13 \mathrm{~L}$ & $M, 42$ & Yes & 2 & - & - & - & 43 & IV & Improved & 3 & Conservative & $\mathrm{Bad}$ \\
\hline 14 & $M, 43$ & No & 2 & Yes & 3 & Alcohol & 22 & III & No & 2 & Conservative & Good \\
\hline $15 \mathrm{R}$ & $M, 38$ & Yes & 2 & - & - & Alcohol + CS & 30 & IV & Worse & 3 & THR & $\mathrm{Bad}$ \\
\hline $15 \mathrm{~L}$ & $\mathrm{M}, 38$ & No & 2 & - & - & - & 32 & IV & Worse & 3 & THR & $\mathrm{Bad}$ \\
\hline 16 & $M, 39$ & Yes & 2 & Yes & 3 & Alcohol & 41 & IV & No & 2 & Conservative & Good \\
\hline 17 & $M, 38$ & No & 2 & Yes & 3 & Alcohol + CS & 23 & II & No & 2 & Conservative & Good \\
\hline 18 & $M, 31$ & Yes & 2 & Yes & 3 & Alcohol & 56 & II & Worse & 3 & THR & $\mathrm{Bad}$ \\
\hline
\end{tabular}

Radiological stage, according to Ficat. ${ }^{11} \mathrm{CS}=$ corticosteroids. ON volume (\%), according to Holman et al..$^{10}$ Histological type, according to Arlet and Durroux. ${ }^{12}$ $\mathrm{THR}=$ total hip replacement. Outcome $=$ "good" = no radiological deterioration; "bad" = increase in Ficat stage. 
Table 3 Comparison of groups according to radiological stability (good outcome) or progression (bad outcome)

\begin{tabular}{llll}
\hline Parameters & $\begin{array}{l}\text { Good outcome } \\
(n=10)\end{array}$ & $\begin{array}{l}\text { Bad outcome } \\
(n=10)\end{array}$ & p Value \\
\hline Age (y) (SD) & $39(6)$ & $47(11)$ & $\mathrm{NS}^{\star}$ \\
Histological type & 0 & 0 & \\
$\quad$ I & 5 & 2 & $\mathrm{NS} \dagger$ \\
II & 2 & 4 & \\
III & 3 & 4 & $\mathrm{NS} \dagger$ \\
IV & 6 & 4 & \\
Aetiological factors & 4 & 6 & $0.0722 \dagger$ \\
$\quad$ Alcohol & 1 & 3 & \\
$\quad$ Corticosteroids & 7 & 2 & \\
$\quad$ Both & $22(10)(5-41)$ & $45(20)(18-90)$ & $0.0051^{\star}$ \\
Asymptomatic hips at entry & & & \\
Volume of ON $(\%):$ mean (SD) (ranges)
\end{tabular}

^ Mann-Whitney, $\uparrow \chi^{2}$ test.

for the quantitative parameters and the $\chi^{2}$ test for the qualitative parameters.

\section{Results}

Table 2 shows the results. At two years, nine femoral heads had collapsed (progression to stages III/IV). In the tenth hip (patient 10 who was receiving corticosteroid treatment for systemic lupus erythematosus, necrotic volume $18 \%$ ), the head had not collapsed but rapid chondrolysis had occurred (so called "ischaemic coxopathy"13), the clinical condition had deteriorated, and total hip replacement had been required, so the outcome in this case was also classified as poor. Seven hips remained free from symptoms and four showed clinical improvement or had become non-symptomatic. All these 11 hips corresponded to good radiological results (stable stage II) except in one case where clinical improvement contrasted with radiological deterioration (patient 13, left hip).

Distribution of cases according to the main outcome criterion (table 3 ) showed that neither age nor histological type nor aetiological factors influenced the outcome. Only the volume of necrotic bone was significantly greater in radiologically progressive than in stable cases. Lastly, initially asymptomatic necrosis was more frequent in the good outcome group (borderline significance level).

\section{Discussion}

Core decompression gave good results in half the 20 hips of strictly defined stage II ON. We had no control series but the medical literature is more pessimistic concerning the results of conservative treatment at two years, with satisfactory results evaluated at a mean of $31 \%$ for this stage. ${ }^{2}$ Inversely, again for stage II ON, core decompression gave $65 \%$ of good results at 30 months. Our results are less good but the series is small.

These results in the medical literature do not differentiate between symptomatic and asymptomatic stage II necrotic hips. Of our nine asymptomatic $\mathrm{ON}$, only two progressed to symptomatic stage III. In the same conditions, six of 19 hips in the retrospective series of Jergesen et $a l^{14}$ became symptomatic at three years, but eight developed symptoms later; if stage II ON is silent, this indicates that the disease is recent but is not a guarantee of future stability.
The worst outcomes were in the patients with the greatest volume of necrosis. Using the threshold proposed by Holman et al, ${ }^{10}$ in our series seven of eight whose necrotic volume was $\leqslant 23 \%$ did not deteriorate (the patient with "ischaemic coxopathy" was the only exception) and nine of $12 \mathrm{ON}$ whose volume was greater than $23 \%$ deteriorated and required total hip replacement. However, it should be noted that at least two cases had a large volume of necrotic bone $(32 \%$ and $41 \%)$ but did not collapse (patients 1 and 16). It can be considered that core decompression was beneficial in these two cases at least. These two patients admitted alcohol abuse but were not receiving corticosteroids; their contralateral hips were stage III and the study hip was initially silent in one case and painful in the other.

Although calculation methods differed, all authors who measured volume of necrotic bone came to the same conclusion: femoral head collapse is related to the extent of necrosis and not to treatment. Lafforgue et $a l,{ }^{7}$ in their retrospective study of $31 \mathrm{ON}$, observed that in the cases with an unfavourable radiological and clinical course the necrotic area was significantly greater than that of patients with a favourable outcome. Koo and colleagues ${ }^{8}$ carried out a prospective randomised study of core decompression versus conservative treatment in 37 patients. The need for later hip replacement was similar in both groups. The difference in outcome, however, was related to the volume of necrotic bone. Their calculation method, however, required axial MRI slices, which are not always available and calculation of the angles filled by necrosis is not easy. We were able to carry out calculation by this method in 12 patients (results not given) and the differences between our two groups were not significant (with, it is true, an intraobserver coefficient of variation of $21 \%$ !). The method of Holman et al finally seems the most satisfactory and probably the simplest to use as current MRI devices are capable of directly calculating necrotic volume according to predetermined parameters.

If the volume of necrotic bone is the main factor in the outcome, it is evidently important not only to define this volume as precisely as possible but also to follow its progression. A decrease in necrotic volume has in fact been reported in renal transplant recipients ${ }^{6}{ }^{15}$ and in patients receiving corticosteroids. ${ }^{16}$ In the second instance, regression occurred in $45 \%$ of patients with purely "magnetic" ON and took place in the first year after the start of long term corticotherapy.

In the future, therefore, the volume of necrotic bone will have to be taken into account both in studies dealing with the natural history of the disease and in those relating to the results of core decompression. This new parameter will perhaps permit better assessment of the results of conservative treatment. ${ }^{14}$

1 Mont MA, Hungerford DS. Non-traumatic avascular necrosis of the femoral head. J Bone Joint Surg 1995;77A:459-74. 
2 Mont MA, Carbone JJ, Fairbank AC. Core decompression versus non-operative management for osteonecrosis of the versus non-operative management for osteon
hip. Clin Orthop Rel Res 1996;324:169-78.

3 Mitchell DG, Rao VM, Dalinka MK, Spritzer CE, Alavi A, Steinberg ME, et al. Femoral head avascular necrosis: correlation with MR imaging, radiographic staging, radionuclide imaging, and clinical findings. Radiology 1987; 162:709-15.

4 Beltran J, Knight CT, Zuelzer WA, Morgan JP, Shwendeman LJ, Chandnani VP, et al. Core decompression fo avascular necrosis of the femoral head: correlation between long term results and preoperative MR staging. Radiology 1990;175:533-6.

5 Chan TW, Dalinka MK, Steinberg ME, Kressel HY. MRI appearance of the femoral head osteonecrosis following core decompression and bone grafting. Skeletal Radiol 1991;20:103-7.

6 Le Parc JM, André T, Helenon O, Benoit J, Paolaggi JB, Kreis H. Osteonecrosis of the hip in renal transplant recipients. Changes in functional status and magnetic resonance imaging findings over three years in three hundred five patients. Rev Rhum Engl Ed 1996;63:413-20.

7 Lafforgue P, Dahan E, Chagnaud C, Schiano A, Kabbarian M, Acquaviva PC. Early stage avascular necrosis of the femoral head. MR imaging for prognosis in 31 cases with a least 2 years of follow-up. Radiology 1993;187:199-204.

8 Koo KH, Kim R, Koo GH, Song HR, Jeong ST. Preventing collapse in early osteonecrosis of the femoral head. J Bone Joint Surg 1995;77B:870-4.
9 Koo KH, Kim R. Quantifying the extent of osteonecrosis of the femoral head. A new method using MRI. J Bone Joint Surg 1995;77B:875-80.

10 Holman AJ, Gardner GC, Richardson MC, Simkin PA. Quantitative magnetic resonance imaging predicts clinical outcome of core decompression for osteonecrosis of the femoral head. J Rheumatol 1995;22:1929-33.

11 Ficat RP. Idiopathic bone necrosis of the femoral head. Early diagnosis and treatment. J Bone Joint Surg 1985; 67B:3-9.

12 Arlet J, Durroux R. Diagnostic histologique précoce de l'ostéonécrose aseptique de la tête fémorale par le forage-biopsie. In: Arlet J, Ficat P, eds. Compte rendu du 1er Symposium International sur la Circul

13 Arlet J, Ficat P, Mazières B. Les coxarthroses d'origine ischémique. La coxopathie ischémique. Revue du Rhumatisme et des Maladis Osteo-articulairs 1978;45:401-8.

14 Jergesen HE, Khan AS. The natural history of untreated asymptomatic hips in patients who have non-traumatic asymptomatic hips in patients who have non-traum
osteonecrosis. J Bone Joint Surg 1997;79A:359-63.

15 Kopecky KK, Braunstein EM, Brandt KD, Filo RS, Leapman SB, Capello WN, et al. Apparent avascular necrosis of the hip: appearance and spontaneous resolution of MR findings in renal allograft recipients. Radiology 1991;179:523-7.

16 Sakamoto M, Shimizu K, Iida S, Akita T, Moriya H, Natawa Y. Osteonecrosis of the femoral head. A prospective study with MRI. J Bone Joint Surg 1997;79B:213-19. 